\title{
TRATAMIENTO CONTABLE DE LOS ACTIVOS BIOLÓGICOS Y LOS PRODUCTOS AGRÍCOLAS
}

\section{ACCOUNTING TREATMENTS OF BIOLOGICAL ASSETS AND AGRICULTURAL PRODUCTS}

Rubén Darío Marrufo Garcia

Universidad Dr. Rafael Belloso Chacin

Facultad de Ciencias Administrativas

Maracaibo, Estado Zulia, Venezuela rmarrufo@urbe.edu.ve

\author{
Abel María Cano Morales \\ Universidad de Medellin \\ Facultad de Ciencias Económicas y Administrativas \\ Medellin, Antioquia, Colombia. \\ amcano@udem.edu.co
}

Fecha de recepción: 13/10/2020 - Fecha de revisión: 11/01/2021 - Fecha de aprobación: 20/01/2021

DOI: https://doi.org/10.36995/j.visiondefuturo.2021.25.02R.002.es

\section{RESUMEN}

Es preciso mencionar que este trabajo que se presenta, como resultado de investigación, corresponde al manejo y tratamiento contable que puede darse a los Activos Biológicos en las empresas Latinoamericanas del sector agropecuario, y tiene como finalidad demostrar la influencia que existen entre la importancia proporcionada a la contabilidad financiera bajo (NIC/NIIF) y la poca reciprocidad del manejo contable y las prácticas contables que se aplican efectivamente en el sector agrícola, especialmente en las Pymes, ocasionando con ello algunas fisuras. Sin embargo, se puede afirmar que las razones de las posibles fisuras que puedan existir, se atribuyen a que las normas generales de contabilidad actuales no se adaptan muy bien a las particularidades del sector de la agricultura y son relativamente difíciles, y costosas en su implementación, en el caso Latinoamericano, es preciso mencionar que la Norma Internacional de Contabilidad 41. (NIC 41), cuando son plenas y la sección 34 para Pymes, prescriben el tratamiento contable de la actividad agropecuaria, introduciendo avances significativos en el reconocimiento de los resultados por la transformación de bienes biológicos generados en el esfuerzo conjunto del ser humano y la naturaleza.

PALABRAS CLAVE: Activos Biológicos; Productos Agrícolas; Fincas Colombianas; Normas Contables.

\section{ABSTRACT}

It should be mentioned that this work that is presented, as a result of research, corresponds to the management and accounting treatment that can be given to Biological Assets in Latin American companies in the agricultural sector, and its purpose is to demonstrate the influence that exists between the importance given to low financial accounting (IAS / IFRS) and poor reciprocity in accounting management and accounting practices that are "Visión de Futuro" Año 18, Volumen No 25 No 2, Julio - Diciembre 2021 - Pág 40 - 62
URL de la Revista: http://visiondefuturo.fce.unam.edu.ar/index.php/visiondefuturo/index
URL del Documento: https://visiondefuturo.fce.unam.edu.ar/index.php/visiondefuturo/issue/view/21
ISSN 1668 - 8708 - Versión en Línea
E-mail: revistacientifica@fce.unam.edu.ar 
effectively applied in the agricultural sector, especially in SMEs, thus causing some cracks. However, it can be stated that the reasons for the possible fissures that may exist are attributed to the fact that the current general accounting standards do not adapt very well to the particularities of the agriculture sector and are relatively difficult, and costly to implement. In the Latin American case, it should be mentioned that International Accounting Standard 41. (IAS 41), when they are full and section 34 for SMEs, prescribe the accounting treatment of agricultural activity, introducing significant advances in the recognition of results. for the transformation of biological goods generated in the joint effort of human beings and nature.

KEY WORDS: Biological Assets; Agricultural Products; Colombian Farms; Accounting Standards.

\section{INTRODUCCIÓN}

El propósito de este artículo, es dar mayor claridad, es preciso mencionar que la Norma Internacional de Contabilidad 41. (NIC 41), cuando son plenas y la sección 34 para Pymes, prescriben el tratamiento contable de la actividad agropecuaria, introduciendo avances significativos en el reconocimiento de los resultados por la transformación de bienes biológicos generados en el esfuerzo conjunto del ser humano y la naturaleza. Cabe anotar que en el tratamiento contable de los activos biológicos el hombre es un elemento importante pero no necesario para que dicho proceso se realice. Debido a que la (NIC 41), sólo considera a los bienes biológicos cuyo resultado sea producto del hombre y la naturaleza. En ese sentido, muchas empresas, fincas, latifundios, entre otros, en Colombia carecen de procedimientos administrativos y contables para llevar el registro y control de la actividad agropecuaria.

Ahora bien, con la entrada en vigencia de las normas internacionales de información financiera en Colombia, es de vital importancia, que las empresas dedicadas a la explotación de los activos biológicos como los son (Ovejas, Arboles, Plantas, Cerdo, Arbustos, vides, frutales entre otros). Adecuen su contabilidad a fin de mostrar la verdadera situación financiera de este tipo de negocio. Además, le dan cumplimiento a la ley 1314 de 2009 el Gobierno colombiano busca utilizar un lenguaje financiero único de alta calidad, comprensible y de cumplimiento exacto, con la aplicación de las normas internacionales de información financiera es de vital importancia evaluar los efectos en la elaboración y presentación de los estados financieros, así como también la comparación con las normas existentes, la globalización exige información financiera que sea comprable.

En ese sentido, para tener una buena información contable y financiera se requiere conocimiento del activo biológico desde su gestación hasta la madurez del mismo, puesto que

\footnotetext{
"Visión de Futuro" Año 18, Volumen No 25 N², Julio - Diciembre 2021 - Pág 40 - 62

URL de la Revista: http://visiondefuturo.fce.unam.edu.ar/index.php/visiondefuturo/index

URL del Documento: https://visiondefuturo.fce.unam.edu.ar/index.php/visiondefuturo/issue/view/21

ISSN 1668 - 8708 - Versión en Línea

E-mail: revistacientifica@fce.unam.edu.ar
} 
todos los desembolsos que se dan en la etapa de crecimiento serán llevando a una cuenta del estado de situación financiera en el rubro de activo no corriente denominada activo biológico en crecimiento, que se quiere expresar con esto que los costos asociados al crecimiento de la planta y/o animal, como lo son; la labor directa e indirecta, suministros, insumos, honorarios entre otros no se registraran en una cuenta nominal, cuando la planta y/o el animal ya estén en su madurez reproductiva se reclasifica la cuenta de activo biológico en crecimiento a una cuenta denominada activo biológico en producción, cuando eso suceda, los costos asociados a la producción serán registrado al resultado del ejercicio.

Por lo antes dicho, es necesario llevar un buen control interno, en lo concerniente al manejo de los inventarios, debido a que la requisición que se hace en el almacén, se debe especificar el activo biológico asociado, es decir si es para la etapa de crecimiento se le dará un debito a la cuenta de activo biológico en crecimiento contra un crédito al inventario, si está en la etapa de producción, se le dará un debito a la cuenta de gasto asociada a la producción contra un crédito al inventario. En ese sentido, la gerencia de la organización debe crear centros de costos, por cada etapa que se da en la cosecha y/o crianza del animal, a fin de tener los costos identificados por cada actividad.

Por otra parte, al hablar de la aplicación de (NIIF), al interior de las fincas, no es solo poseer personal conocedor en el área contable o financiera, o cumplir con toda la normatividad vigente. Más allá de estos aspectos, todas las organizaciones están mostrando impactados en sus negocios por este proceso de aplicación de (NIIF), y quien más que las propias empresas apoyadas en su gestión administrativa, para determinar las variaciones de su modelo de negocio, y la influencia de esta normatividad sobre su planeación de manera transversal y holística.

Cabe anotar que la actividad agrícola presenta discrepancia con otras actividades llevadas a cabo por las unidades de negocio para lograr la utilidad, de allí radica que con el análisis comparativamente de las normas actualmente aplicadas para la información de la actividad agrícola y la revisión del tratamiento contable actual de la actividad agrícola bajo las Normas Internacionales de Información Financiera (NIIF), han sido el punto de partida de esta investigación. Por lo tanto, este segmento sirve como base para el desarrollo de la investigación propia en la que se intenta identificar los aspectos determinados en el proceso de producción agrícola, los activos biológicos y la transformación biológica. También se ofrecen algunos métodos más prácticos para su reconocimiento, medición e informe como alternativa a los tratamientos actuales. Al final, los resultados presentados en este artículo, se fundamentan con base a la literatura científica contemporánea que existe sobre ese tema, que actualmente consideramos, no es muy amplia.

\footnotetext{
"Visión de Futuro" Año 18, Volumen N²5 N², Julio - Diciembre 2021 - Pág 40 - 62 URL de la Revista: http://visiondefuturo.fce.unam.edu.ar/index.php/visiondefuturo/index URL del Documento: https://visiondefuturo.fce.unam.edu.ar/index.php/visiondefuturo/issue/view/21 
Indudablemente es preciso aclarar que, durante el último decenio, ha habido una proliferación de pronunciamientos contables que indican que los autores de las normas contables en todo el mundo están abandonando progresivamente el modelo de costo histórico tradicional y están propagando de manera activa el paradigma del valor razonable. En este sentido, (Barlev y Haddad 2003). Sostienen que la contabilidad bajo el método de valor razonable tiene la capacidad de mejorar la función administrativa organizacional, al proporcionar información relevante a las partes interesadas, apaciguando así las controversias sociales. Que permiten sostener que, lejos de reducir el conflicto y la alienación en el sector agrícola, el enfoque de valor razonable se basa en los ideales económicos neoclásicos que no son propicios para la contabilidad emancipadora, todo ello basados en la noción planteada por Carl Marx en el Capital, y que tácitamente dice: "Marx rompe con estas concepciones al afirmar en El Capital que el valor de uso y las determinaciones del valor no son fuente del fetichismo: El carácter místico de la mercancía no deriva, por tanto, de su valor de uso. Tampoco proviene del contenido de las determinaciones de valor". (Marx, 2002, pág. 87)", razón por la cual se menciona el fetichismo de los productos básicos, y nos permite mediante este documento analiza el papel ideológico de la Norma Internacional de Contabilidad (NIC 41) en la legitimación de los conflictos sociales en el contexto del comercio justo de las empresas agrícolas, que se han visto obligadas por la legislación nacional a adoptar un valor justo en toda regla Modelo contable conforme a las reformas de ajuste estructural instituidas por el Banco Mundial.

Por lo tanto, nuestro trabajo consiste en observar las preexistencias de algunas fisuras entre la importancia dada a la contabilidad y el poco nivel de contabilidad y prácticas contables que se aplican realmente en el sector agrícola. Sin embargo, se puede afirmar que las razones de estas fisuras, se atribuyen a que las normas generales de contabilidad actuales no se adaptan muy bien a las particularidades de la agricultura y son relativamente difíciles, y costosas en su implementación. Por lo tanto se sugiere la información contable Agrícola de la base de datos de la bolsa nacional agropecuaria y la Norma Internacional de Contabilidad para la Agricultura (NIC 41), ya que se convierten en elementos clave para mejorar el uso de la contabilidad en las fincas colombianas, No obstante y haciendo alusión a cuáles son las principales contribuciones de la (NIC 41) podemos precisar que proporciona un marco conceptual sólido, pero que podría necesitar instrumentos adicionales para su implementación en la práctica, dadas las limitaciones del sector agrícola.

Finalmente se presentan las definiciones y los planteamientos de los principales autores en torno a las Normas Internacionales de Información Financiera, de los Activos biológicos y su reconocimiento inicial, y posterior, de los Productos agrícolas, de la Medición a la luz de

\footnotetext{
"Visión de Futuro" Año 18, Volumen No 25 N², Julio - Diciembre 2021 - Pág 40 - 62

URL de la Revista: http://visiondefuturo.fce.unam.edu.ar/index.php/visiondefuturo/index

URL del Documento: https://visiondefuturo.fce.unam.edu.ar/index.php/visiondefuturo/issue/view/21

ISSN 1668 - 8708 - Versión en Línea

E-mail: revistacientifica@fce.unam.edu.ar
} 
la sección 34, de los Costos estimados del Punto de Venta, y de la Determinación del Valor Razonable y de los registros contables de una Cosecha de guanábanas como ejemplo, y finalmente presentar los planteamientos de algunos autores sobre la metodología que se debe seguir para la Valoración de los activos Biológicos, para finalmente concluir como debe ser el tratamiento contable de los activos biológicos y los productos agrícolas, por otra parte se presenta como una conclusión importante como este tipo de actividad económica, y la implementación de las NIIF es importante por cuanto sus estándares son más aproximados a la realidad, lo que facilita el proceso contable de los activos biológicos, y la toma de decisiones.

\section{DESARROLLO}

\subsection{Definición de las Normas Internacionales de Información Financiera}

Es preciso hacer mención que la investigación realizada, tiene como principal objetivo, analizar el tratamiento contable de los activos biológicos y de los productos agrícolas, haciendo claridad, que la actividad agrícola es en comparación con otras actividades comerciales que dependen de las condiciones naturales y ambientales diferente, por lo tanto ello implica que reconocer que cualquier actividad agrícola que se realice, está estrechamente ligada a la posición geográfica donde se ejerce, razón por la cual mediante el trabajo desarrollado, se pretende identificar los posibles impedimentos que se puedan presentar en la aplicación práctica de la Norma Internacional de Contabilidad 41 (NIC 41) y referir las posibles soluciones para superarlos, de igual manera cabe mencionar que este trabajo se sustenta en los principales postulados teóricos de (Bastián. 2008), (Corona. 2014), (NIC 41), entre otros autores, y se enmarca bajo una metodología descriptiva, documental, y analítica utilizando la hermenéutica sobre el tratamiento contable de los activos biológicos.

No obstante y para comodidad de los lectores, citaremos algunas definiciones en torno a las Normas Internacionales de Información Financiera en adelante (NIIF) y de las Normas Internacionales de Contabilidad en adelante (NIC), según (Romero 2011), manifiesta que Las Normas Internacionales de Información Financiera (NIIF) y Normas Internacionales de Contabilidad (NIC) son un conjunto de Normas, leyes así como también de principios que establecen la información en la cual se deben presentar los estados financieros además la forma de cómo se debe presentar esta información en dichos estados. Por su parte (Warren, Reeves y Duchac. 2015), expresa que las NIC-NIIF es un modelo contable que toma como punto de partida el principio contable de la entidad en funcionamiento, y todas las normas que contiene van encaminadas a recoger contablemente con el suceder del día a día de los sujetos contables, con un fin fundamental que es la elaboración y presentación de los estados financieros del ejercicio económico.

\footnotetext{
"Visión de Futuro" Año 18, Volumen N²5 N² 2, Julio - Diciembre 2021 - Pág 40 - 62 URL de la Revista: http://visiondefuturo.fce.unam.edu.ar/index.php/visiondefuturo/index

URL del Documento: https://visiondefuturo.fce.unam.edu.ar/index.php/visiondefuturo/issue/view/21 
Por su parte, (Besteiroy Marracín. 2011), dicen que las Normas Internacionales de Información Financiera conciernen a un conjunto único de normas de exigibilidad, mundialmente aceptadas, comprensibles además de alta calidad basados en principios de manera articulada; estos exhortan que los estados financieros tengan información comparable, transparente, así como también de mucha calidad, que ayude a los inversores, y a otros usuarios, a tomar decisiones económicas. Para efecto de esta investigación se fija posición con Romero (2011), quien manifiesta que las Normas Internacionales de Información Financiera (NIIF) y Normas Internacionales de Contabilidad (NIC) son un conjunto de Normas y leyes.

Así mismo, (Romero. 2011), (Warren y Col. 2007), (Besteiroy Marracín 2011), asumen la postura sobre la importancia de las Normas Internacionales de Información Financiera, NIIF en las empresas, determinado que los usuarios de estas normas, requieren un nivel de información estándar para poder clasificar y evaluar su empresa, es decir, coadyuva a que el impacto de las NIIF, se reflejen en la productividad de las mismas y en el cumplimiento de las Leyes que rigen la Contabilidad.

Para efecto de esta investigación se fija posición con (Romero. 2011), quien manifiesta que las Normas Internacionales de Información Financiera (NIIF) y Normas Internacionales de Contabilidad (NIC) son un conjunto de Normas y leyes. Ahora bien, desde las posturas de los autores si infiere que los productores agrícolas colombiana adopten las normas Internacionales de información financiera, cumpliendo con lo que establece la ley 1314 del año 2009, además mostraran una información financiera con más claridad para los accionistas y los que requieran información de la empresa.

\subsubsection{La Norma Internacional de Contabilidad No.41. Agricultura, y el tratamiento contable de los "Activos Biológicos"}

Es justo mencionar que la NIC 41 "Agricultura" tiene como objetivo establecer normas para el tratamiento contable, la presentación en los estados financieros y la información a revelar en relación con la actividad agrícola. La NIC 41 se aplica a los siguientes elementos siempre que estén relacionados con la actividad agrícola:

1. Activos biológicos.

2. Productos agrícolas en el punto de cosecha o recolección.

3. Subvenciones del gobierno relacionadas con la actividad agrícola.

No obstante, es importante destacar que la NIC 41 sólo se aplica hasta el punto de cosecha. A partir de ese momento, la producción, así como los procesos de elaboración que utilicen como materias primas productos agrícolas se regirán por lo dispuesto en la NIC 2

\footnotetext{
"Visión de Futuro" Año 18, Volumen No 25 N², Julio - Diciembre 2021 - Pág 40 - 62

URL de la Revista: http://visiondefuturo.fce.unam.edu.ar/index.php/visiondefuturo/index

URL del Documento: https://visiondefuturo.fce.unam.edu.ar/index.php/visiondefuturo/issue/view/21

ISSN 1668 - 8708 - Versión en Línea

E-mail: revistacientifica@fce.unam.edu.ar
} 
"Inventarios". En algunas ocasiones, la inclusión determinados productos agrícolas bajo la NIC 41 no es clara y es necesario conocer el destino de los mismos, que será el que defina si se aplica la NIC 41 o la NIC 2.

Cabe mencionar que la actividad agrícola es definida en la (NIC 41) como la gestión por parte de una entidad de la transformación y recolección de activos biológicos para destinarlos a la venta, para convertirlos en productos agrícolas o en otros activos biológicos adicionales. La actividad agrícola en sus distintas formas a saber (silvicultura, ganadería, entre otros) presenta tres características comunes:

A. Capacidad de cambio. Tanto las plantas como los animales son capaces de experimentar transformaciones biológicas.

B. Gestión del cambio. La gerencia facilita las transformaciones biológicas promoviendo las condiciones necesarias para que la transformación tenga lugar.

C. Medición del cambio. tanto el cambio cualitativo como cuantitativo fruto de la transformación biológica es medido y controlado de forma sistemática por la gerencia.

\section{Qué son los Activos biológicos y cuál es su tratamiento contable}

Cabe mencionar que (Mora 2008), manifiesta que son los animales y plantas vivientes que son controlados por una empresa como resultado de eventos pasados. Los activos biológicos incluyen aquellos controlados mediante su posesión y aquellos de un arreglo legal o similar además son reconocidos como activos conforme otras normas. Dentro de los activos biológicos se pueden distinguir aquellos que son que son en sí mismo el producto primario, es decir activo biológico consumible, de aquellos que no son en sí mismo el producto primario, si no los que generan dichos productos, por ejemplo, árboles frutales, ganados. También se distingue, a efectos contables, entre activos biológicos maduros, cuando están en condiciones de ser recolectados, e inmaduros cuando todavía no son cosechables.

Por su parte, (Bastián 2008), manifiesta que los activos biológicos son las plantas además de animales vivos que son capaces de experimentar transformaciones biológicas, con el objeto de dar productos agrícolas, estos se contabilizan como existencias o bien para convertirlos en otros activos biológicos diferentes. Por otra parte (Corona 2014), expresa que es la gestión por parte de una entidad, de las transformaciones de carácter bilógico y cosechas de activos bilógicos para destinarlo a la venta, para convertirlos en productos agrícolas o en otros activos bilógicos adicionales. Según NIIF 13, los productos agrícolas cosechados 0 recolectados que procedan de activos biológicos de una entidad se medirán a su valor razonable menos los costos de venta en el punto de cosecha o recolección. Una vez evaluada

\footnotetext{
"Visión de Futuro" Año 18, Volumen No 25 N² 2, Julio - Diciembre 2021 - Pág 40 - 62 URL de la Revista: http://visiondefuturo.fce.unam.edu.ar/index.php/visiondefuturo/index

URL del Documento: https://visiondefuturo.fce.unam.edu.ar/index.php/visiondefuturo/issue/view/21

ISSN 1668 - 8708 - Versión en Línea

E-mail: revistacientifica@fce.unam.edu.ar
} 
las posturas teóricas se fija posición con lo manifestado con la NIIF, al decir que los activos biológicos se medirán al valor razonable menos los costos de venta.

La International Accounting Standards Board (2010), plantea que es un animal vivo o una planta. De acuerdo con el Diccionario de Contabilidad, Auditoría y Control de Gestión (Mora. 2008) activos biológicos representan un animal vivo o una planta, que son controlados por una empresa como resultados de eventos pasados. En cuanto al reconocimiento de los activos biológicos, International Accounting Standards Board (2011) expresa que la entidad reconocerá un activo biológico o un producto agrícola bajo las siguientes condiciones:

La entidad controle el activo como resultado de sucesos pasados;

1. Sea probable que fluyan a la entidad beneficios económicos futuros asociados con el activo;

2. El valor razonable o el costo del activo puedan ser medidos de forma fiable.

Por otra parte, (Figuera 2018), manifiesta que una empresa debe reconocer un activo biológico o producto agrícola cuando:

a) La empresa controla el activo como resultado de eventos pasados.

b) Es probable que un beneficio económico futuro asociado con el activo fluya para la compañía.

3. El valor razonable o el costo del activo puede ser medido confiablemente.

De manera tal, que, diferenciando los planteamientos expuestos, se observa similitud entre los contextos dados para el reconocimiento de los activos biológicos: control del activo, el flujo de los beneficios económicos, el costo o valor los cuales deben ser medidos confiablemente. La medición de los activos biológicos, según la NIC 41, esta se debe realizarse a valor razonable menos los costos del punto de venta. El valor razonable o se obtiene descontando al valor de mercado los costos de transporte y otros ineludibles para trasladar la producción al centro de comercialización o sea los costos hasta el punto de venta. En efecto el valor razonable de un mismo bien puede no ser igual para todas las entidades, o dentro de la misma, si posee campos en localidades distantes. Puesto que influye su ubicación geográfica, así como también la cercanía o no a los puestos de ventas de los productos. Los productos agrícolas obtenidos estos deben medirse en el sitio de la cosecha o recolección a valor razonable menos los costos estimados hasta el punto de venta, En el caso de que el activo biológico esté en una etapa de crecimiento y/o desarrollo, para la cual no existe unos precios de mercado, estos se calculará el valor razonable aplicando el valor actual de los flujos de fondos netos.

\footnotetext{
"Visión de Futuro" Año 18, Volumen No 25 N², Julio - Diciembre 2021 - Pág 40 - 62

URL de la Revista: http://visiondefuturo.fce.unam.edu.ar/index.php/visiondefuturo/index

URL del Documento: https://visiondefuturo.fce.unam.edu.ar/index.php/visiondefuturo/issue/view/21

ISSN 1668 - 8708 - Versión en Línea

E-mail: revistacientifica@fce.unam.edu.ar
} 


\section{Reconocimiento y medición de los Activos Biológicos}

Es preciso mencionar que para el reconocimiento de los activos biológicos debe cumplir con las tres condiciones establecidas en el marco conceptual y que reza textualmente, para el reconocimiento de activos es necesario:

1. Que la entidad controle el activo como resultado de sucesos pasados.

2. Sea probable que la entidad reciba los beneficios económicos futuros asociados al activo.

3. El valor razonable o el coste del activo puedan ser medidos de forma fiable.

No obstante, debemos mencionar que el criterio de valoración establece que todo activo biológico se reconocerá por su valor razonable, a su valor razonable menos los costos de venta. $Y$ entre los costos de venta se deben incluir:

A. Las Comisiones pagadas a los intermediarios.

B. Los Gravámenes e impuestos.

Por otra parte, la Norma establece que en ningún caso se deben incluir los costos de transporte o similares en la determinación del valor razonable del activo biológico. Por otra parte, pueden existir contratos para la venta futura de un activo biológico. Los precios fijados en dicho contrato en ningún caso podrán tomarse como base para determinar el valor razonable. La NIC 41 establece la presunción de que el valor razonable del activo se puede estimar con fiabilidad. A la hora de determinar el valor razonable pueden darse 3 situaciones:

1. Existencia de un mercado activo. En este caso el precio de cotización en dicho mercado activo es la base adecuada para determinar el valor razonable del activo. Por ejemplo, en el caso de los cereales o el azúcar existen mercados spot en los que se determina el precio de la materia prima que debería servir de base para la valoración de dichos activos biológicos.

2. Inexistencia de un mercado activo. En este supuesto para la determinación del valor razonable como referente la siguiente información:

a. El precio de la transacción más reciente en el mercado, siempre que no se hayan modificado las condiciones desde la fecha de la transacción hasta la fecha del periodo del que se informa.

b. Los precios de mercado de activos similares, ajustados para reflejar las diferencias existentes.

3. Imposibilidad determinar el valor razonable. En ese caso, el activo biológico se debe medir a su precio coste corregido de amortizaciones y deterioro de valor, exclusivamente en el momento de su reconocimiento.

\footnotetext{
"Visión de Futuro" Año 18, Volumen No 25 N², Julio - Diciembre 2021 - Pág 40 - 62

URL de la Revista: http://visiondefuturo.fce.unam.edu.ar/index.php/visiondefuturo/index

URL del Documento: https://visiondefuturo.fce.unam.edu.ar/index.php/visiondefuturo/issue/view/21

ISSN 1668 - 8708 - Versión en Línea

E-mail: revistacientifica@fce.unam.edu.ar
} 
Finalmente es frecuente que los activos biológicos se presenten combinados con otro tipo de activos. Por ejemplo, en una plantación de soya se combinan los terrenos con la planta de soya (activo biológico). Para la valoración de este tipo de activo biológico se puede tomar como valor razonable el conjunto de la explotación y deducirle el valor por separado de los terrenos combinados.

\section{Reconocimiento de ganancias y pérdidas.}

Cabe anotar que la NIC 41 establece que las pérdidas o ganancias tanto en el reconocimiento inicial de un activo biológico como los cambios en su valor razonable se registrarán en la cuenta de resultados, nunca en el patrimonio neto.

Por otra parte (Bastián 2008), expresa que un activo biológico debe ser valorado, En el momento de su reconocimiento inicial, así como también en la fecha de cierre cada balance, según su valor razonable, descontados los costos estimados en el punto de venta, siempre y cuando, que el valor razonable no pueda ser determinado en forma confiable.

Por lo tanto, se tiene que tener en cuenta en el momento de realizar la medición inicial de los activos biológicos en su fase de inicio, una serie de desembolsos cuando el activo biológico está en desarrollo, como por ejemplo los costos asociados desde la alimentación, veterinarios, entre otros no se reconocen en el resultado si no en una cuenta de activo biológico en desarrollo Asimismo, la entidad que hubiera valorado previamente el activo biológico como su valor razonable menos los costos estimados en el punto de venta, continuará haciéndolo así hasta el momento de su venta.

Ahora bien se ilustra con el siguiente ejemplo la medición inicial y posterior de un activo biológico, Supongamos que una empresa dedicada a la cría de ganado vacuno el 02 de febrero de 2015 adquiere dos novillos de dos y tres años de edad, al costo de 2.000.000 pesos, cada uno y el 31 de mayo de ese mismo año se compró alimentos balanceados por un valor de 3.200.000 pesos más IVA del 16\%, insumo que fue consumido por los ejemplares en crecimiento, además se cancela 500.000 pesos por honorarios de veterinario más IVA de $16 \%$ el mismo día a la fecha de cierre el valor razonable de los citados animales, len atención a su evolución biológica es 800.000 pesos cada uno, momento que alcanza la categoría de toros por cambio de edad, según Marrufo y Chirino (2017).

\footnotetext{
"Visión de Futuro" Año 18, Volumen N²5 N², Julio - Diciembre 2021 - Pág 40 - 62

URL de la Revista: http://visiondefuturo.fce.unam.edu.ar/index.php/visiondefuturo/index

URL del Documento: https://visiondefuturo.fce.unam.edu.ar/index.php/visiondefuturo/issue/view/21

ISSN 1668 - 8708 - Versión en Línea

E-mail: revistacientifica@fce.unam.edu.ar
} 
Tabla No.1. Reconocimiento Inicial

\begin{tabular}{|c|c|c|c|c|}
\hline Fecha & Cuentas y Explicación & Referencia & Debe & Haber \\
\hline 02-02-2018 & $\begin{array}{c}\text { AO-01 } \\
\text { Activos Biológicos en Desarrollo }\end{array}$ & MA-01 & 4.000 .000 & \\
\hline & $\begin{array}{l}\text { Cuentas por Pagar P/r Compra de dos } \\
\text { novillos }\end{array}$ & MA-02 & & 4.000 .000 \\
\hline $31-05-2018$ & $\begin{array}{c}\text { AO-02 } \\
\text { Activos Biológicos en Desarrollo }\end{array}$ & MA-01 & 3.200 .000 & \\
\hline $31-05-2018$ & Iva-Compras & MA-03 & 512.000 & \\
\hline $31-05-2018$ & $\begin{array}{l}\text { Cuentas por Pagar P/r Compra de } \\
\text { alimentos para los novillos en crecimiento }\end{array}$ & & & 3.712 .000 \\
\hline $31-05-2018$ & $\begin{array}{c}\text { AO-03 } \\
\text { Activos Biológicos en Desarrollo }\end{array}$ & MA-01 & 500.000 & \\
\hline $31-05-2018$ & Iva-Compras & MA-04 & 80.000 & \\
\hline $31-05-2018$ & Cuentas por Pagar & MA-02 & & 580.000 \\
\hline
\end{tabular}

Fuente: Elaboración propia (Marrufo \& Cano 2019)

Tabla No.2. Reconocimiento Posterior

\begin{tabular}{|c|l|c|c|c|}
\hline Fecha & Cuentas y Explicación & Referencia & Debe & Haber \\
\hline $\begin{array}{c}\text { 31-12- } \\
2018\end{array}$ & AO-04 & MA-05 & & \\
\hline $31-12-$ & Activos Biológicos en Producción & & \\
2018 & Biológicos en Desarrollo P/r & MA-01 & & 7.700 .000 \\
& Desarrollo a Producción. & & \\
\hline $31-12-$ & AO-04 de Activos Biológicos en & & \\
2018 & Activos Biológicos en Producción & MA-05 & & \\
\hline $31-12-$ & Ganancia de Activos No financieros a Valor & MA-06 & & 1.600 .000 \\
2018 & Razonable P/r registro de valor razonable de & & & \\
& los activos biológicos en producción & & & \\
\hline
\end{tabular}

Fuente: Elaboración propia (Marrufo \& Cano 2019)

Tal como se ve en el ejemplo, todos los costos asociados al desarrollo de los novillos, formarán parte de activo bilógico en desarrollo, hasta cumplir con su madurez reproductiva, una vez cumplida su madurez se reclasifica el activo biológico en desarrollo, dándole un debito en este caso al activo biológico en producción puesto que está en su etapa de madurez y reproductiva, a partir de allí todos los costos de mano de obra alimentos entre otros serán reconocidos en una cuenta de resultado.

\footnotetext{
"Visión de Futuro" Año 18, Volumen N$^{0} 25$ N² 2, Julio - Diciembre 2021 - Pág 40 - 62 URL de la Revista: http://visiondefuturo.fce.unam.edu.ar/index.php/visiondefuturo/index

URL del Documento: https://visiondefuturo.fce.unam.edu.ar/index.php/visiondefuturo/issue/view/21

ISSN 1668 - 8708 - Versión en Línea

E-mail: revistacientifica@fce.unam.edu.ar
} 


\section{Reconocimiento y Medición de los Productos agrícolas}

Según la NIC 41, es el producto ya recolectado, procedente de los activos biológicos de la empresa. Asimismo (Bastián 2008), expresa que son las cosechas recolectadas de los activos biológicos de una empresa, el cual debe ser valorado en el punto de la cosecha o recolección según su valor razonable menos los costos de venta.
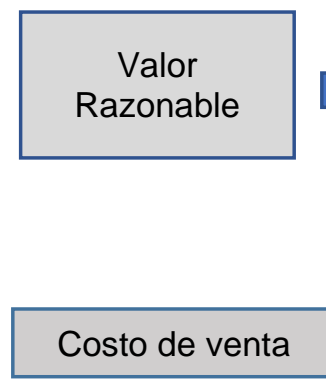
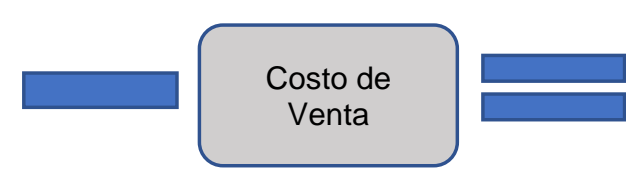

\section{Comisiones}

VALOR EN LOS ESTADOS FINANCIEROS DE LOS ACTIVOS BIOLOGICOS O DE LOS PRODUCTOS AGRICOLAS

Los costos de transporte se excluyen

Los otros costos necesarios para llevar los activos al mercado se excluyen

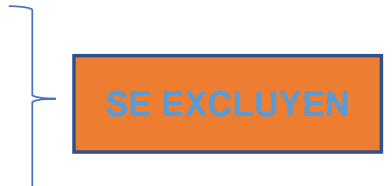

Figura No.1. Sistemas contables de los activos biológicos y aplicación NIC 41

Fuente: Elaboración con base en Rincón Ángel (2017).

Desde el punto de vista contable, es gran importancia que las empresas de área agrícola colombiana, tomen en cuenta el valor razonable del activo biológicos, descontado el costo de venta con el fin de obtener el valor razonable en los estados financieros, de acuerdo a lo planteado el costo de venta debe tener incluido las comisiones, impuestos y gravámenes, mercados organizados entre otros.

\section{Medición de los Productos Agrícolas.}

Tal y como lo establece la Sección 34 (2015), una entidad medirá un activo biológico en el momento del reconocimiento inicial y en cada fecha de sobre la que se informa a su valor razonable menos los costos de venta. Para la determinación del valor razonable una entidad considerara lo siguiente:

A. De existir un mercado activo para un determinado activo biológico o para un producto agrícola en su ubicación y condiciones actuales.

\footnotetext{
"Visión de Futuro" Año 18, Volumen $\mathrm{N}^{0} 25$ No 2, Julio - Diciembre 2021 - Pág 40 - 62

URL de la Revista: http://visiondefuturo.fce.unam.edu.ar/index.php/visiondefuturo/index

URL del Documento: https://visiondefuturo.fce.unam.edu.ar/index.php/visiondefuturo/issue/view/21

ISSN 1668 - 8708 - Versión en Línea

E-mail: revistacientifica@fce.unam.edu.ar
} 
B. Si no se cuenta con un mercado activo, una entidad utilizara uno o más de la siguiente información: Precio de la transacción más reciente en el mercado, precio en el mercado de activos similares, así como también referencia del sector.

C. En algunos casos, el valor razonable puede ser fácilmente determinado, sin un costo o esfuerzo desproporcionado, aun cuando no haya disponible precios o valores determinados para el mercado de un activo biológico en su condición actual.

Desde el punto de vista pragmático (Warren, Reeves y Duchac. 2015), se muestra el siguiente ejemplo, de cómo los administradores y contadores de las empresas del sector agrícola de Colombia deben reconocer y medir en los estados financieros los productos agrícolas.

La empresa frutos del Valle, C.A, se dedica al cultivo de guanábanas, tiene en el año 2015, plantaciones con árboles de la familia biológica Annonaceae, cuyo fruto es la guanábana. Para la cosecha del 2016, desea determinar el costo de dicho fruto, teniendo como referencia que en el mercado el costo de la cosecha es de $\$ 10.500$ pesos de igual Manera FRUTOS EL PUMAREJO incurrió en costos de la cosecha en $\$ 5.000$ peso importe que está registrado en la cuenta de existencia de cultivos en procesos de guanábanas. Por otra parte, los costos estimados del punto de venta $\$ 4.500$ pesos son los siguientes:

Tabla No. 3. Costos estimados del Punto de Venta

\begin{tabular}{|l|r|}
\hline \multicolumn{1}{|c|}{ COSTOS } & \multicolumn{1}{c|}{ IMPORTE } \\
\hline Costos de Transporte & 950,00 \\
\hline Otros Costos Para Colocarlo en el Mercado & 350,00 \\
\hline Comisión de Intermediarios & $1.200,00$ \\
\hline Gastos de Mercados del Productos & 780,00 \\
\hline Impuestos y Gravámenes & 950,00 \\
\hline Otros Costos estimados & 270,00 \\
\hline Total Costos & $\mathbf{4 . 5 0 0 , 0 0}$ \\
\hline
\end{tabular}

Fuente: Elaboración propia (Marrufo \& Cano 2019)

\footnotetext{
"Visión de Futuro" Año 18, Volumen N$^{\circ} 25$ No 2, Julio - Diciembre 2021 - Pág 40 - 62

URL de la Revista: http://visiondefuturo.fce.unam.edu.ar/index.php/visiondefuturo/index

URL del Documento: https://visiondefuturo.fce.unam.edu.ar/index.php/visiondefuturo/issue/view/21

ISSN 1668 - 8708 - Versión en Línea

E-mail: revistacientifica@fce.unam.edu.ar
} 
Tabla No. 4. Determinación del Valor Razonable de la Cosecha de guanábanas

\begin{tabular}{|l|r|}
\hline Valor Razonable de la Cosecha de guanábanas & $10.500,00$ \\
\hline Menos los Costos de Transporte & $-950,00$ \\
\hline Otros Costos Para Colocarlo en el Mercado & $-350,00$ \\
\hline Comisión de Intermediarios & $-1.200,00$ \\
\hline Gastos de Mercados del Productos & $-780,00$ \\
\hline Impuestos y Gravámenes & $-950,00$ \\
\hline Otros Costos estimados & $-270,00$ \\
\hline VALOR DE LA COSECHA & $6.000,00$ \\
\hline Valor de la Cosecha de guanábanas & $6.000,00$ \\
\hline Menos Costo real de la Cosecha & $-5.000,00$ \\
\hline Ajuste del Costo & $\mathbf{1 . 0 0 0 , 0 0}$ \\
\hline
\end{tabular}

Fuente: Elaboración propia (Marrufo \& Cano 2019)

Tabla No. 5. Registro Contable

\begin{tabular}{|c|c|c|c|c|}
\hline Fecha & \multicolumn{1}{|c|}{ Cuentas y Explicación } & Referencia & Debe & Haber \\
\hline $31-12-2018$ & \multicolumn{1}{|c|}{ AO1 } & MA-01 & 6.000 & 5.000 \\
\hline $31-12-2018$ & $\begin{array}{c}\text { Cultivos en Proceso de guanábanas } \\
\text { 31-12-2018 guanábanas }\end{array}$ & $\begin{array}{l}\text { Ganancia por Cambio en el Valor Razonable } \\
\text { P/r Ahora el valor de la Cosecha de } \\
\text { guanábanas es equivalente a \$6.000, a partir } \\
\text { de ahora esta cuenta será trasladada a la } \\
\text { cuenta de inventario y se aplicara en el caso } \\
\text { para NIC plenas la número 2 y para las } \\
\text { Pymes la sección 13 cuyo costo será el valor } \\
\text { indicado anteriormente. }\end{array}$ & MA-03 & 1.000 \\
\hline
\end{tabular}

Fuente: Elaboración propia (Marrufo \& Cano 2019)

Tal como se muestra en el caso práctico, se visualiza el procedimiento contable según lo que dicta la NIC 41 para lo que es el registro de una cosecha de guanábanas desde la valoración inicial hasta la valoración posterior de la misma.

\section{Mercado activo}

En efecto, (Accid. 2009) expresa que el mercado activo son todos aquellos bienes, servicios, en el cual pueden encontrarse en cualquier momento compradores o vendedores para un determinado bien o servicio, y a su vez los precios son conocidos y fácilmente

\footnotetext{
"Visión de Futuro" Año 18, Volumen No 25 N², Julio - Diciembre 2021 - Pág 40 - 62 URL de la Revista: http://visiondefuturo.fce.unam.edu.ar/index.php/visiondefuturo/index

URL del Documento: https://visiondefuturo.fce.unam.edu.ar/index.php/visiondefuturo/issue/view/21 
accesibles para el público, además, refleja transacciones reales, actuales y producidas con regularidad.

Por su parte (Paraninfo 2007), dice que un mercado activo es aquel donde se dan las siguientes condiciones: los bienes o servicios intercambiados son homogéneos, pueden encontrarse en cualquier momento compradores o vendedores para un determinado bien 0 servicio, y los precios son conocidos, fácilmente accesibles para el público, estos precios, además, reflejan transacciones de mercado reales, actuales y producidas con regularidad.

Los axiomas que describen los autores coinciden además exponen de manera detallada la definición mercado activo la cual permite concluir como todos aquellos bienes y servicios intercambiados, estos pueden encontrarse prácticamente en cualquier momento compradores o vendedores para un determinado bien o servicio, y los precios son conocidos, fácilmente accesibles para el público.

\section{Valoración de los activos Biológicos:}

Para (Verón y Marcolini 2011), manifiestan que la generación de polémica sobre la medición de valor razonable en activos biológico. De acuerdo con lo planteado por, (Verón \& Macolini 2011), dicen que "el valor razonable es una medición basada en el mercado, no una medición determinada por la entidad", asimismo se mide utilizando supuestos sobre los participantes incluyendo perfil de riesgo.

Por su parte (Pabón 2010), expresa que el valor razonable da reconocimientos de ganancias y pérdidas no realizadas así como también los precios de un mercado a la fecha de la presentación de los estados financieros, estos pueden ser diferentes con los precios a los que los activos serán traspasado, es menester aclarar que el valor razonable no se tiene como un negocio efectivamente concluido, estos se expresan mediante un esquema de negocio potencial e dial y en este caso no se toma la realidad de los cambios lógicos que se le presentan al activo.

En el caso de los productores de colombina, no cuenta con un mercado activo que les permita medir con fiabilidad los activos biológicos, lo cual genera distorsiones con lo que dicen los autores sobre la valoración de dichos activos.

\section{Inventarios}

Representa la existencia de bienes muebles e inmuebles que tiene la empresa para comerciar con ellos, comprándolos y vendiéndolos tal cual o procesándolos primero antes de venderlos, en un período económico determinado. Según (Block y Hirt 2015), las empresas también pueden solicitar préstamos para conseguir fondos, respaldados con el inventario.

\footnotetext{
"Visión de Futuro" Año 18, Volumen No 25 N², Julio - Diciembre 2021 - Pág 40 - 62 URL de la Revista: http://visiondefuturo.fce.unam.edu.ar/index.php/visiondefuturo/index

URL del Documento: https://visiondefuturo.fce.unam.edu.ar/index.php/visiondefuturo/issue/view/21 
En ese sentido, mientras que el alcance con que se puede emplear la financiación del inventario se basa en la posibilidad de negociación de los bienes pignorados, la estabilidad asociada con su precio y el carácter perecedero del producto. Otro factor significativo es el grado de control físico que el prestamista puede ejercer sobre el producto; es posible relacionar algunos de estos factores con las etapas de la producción del inventario y la naturaleza del control.

Según (Van Horne y Wachowicz 2012), reporta que los inventarios representan un activo razonablemente líquido y, por lo tanto, apropiado para utilizarse como garantía para solicitar préstamos; en este caso el prestamista determina un anticipo porcentual contra el valor en el mercado del colateral, variando dicho porcentaje de acuerdo con la calidad del inventario. Los prestamistas determinan los porcentajes que están dispuestos a anticipar al considerar la facilidad de la venta, la resistencia al deterioro, la estabilidad del precio en el mercado y la dificultad y gastos de vender el inventario para cubrir el préstamo.

Como lo expresa, (Gitman 2014) reporta, que el inventario generalmente es la segunda mejor opción después de las cuentas por cobrar, como garantía colateral para un préstamo a corto plazo; ya que el mismo es atractivo por que comúnmente tiene un valor en el mercado mayor que su valor contable, el cual se utiliza para establecer su valor como garantía colateral. La característica más importante del inventario, avaluado como garantía colateral, es su comerciabilidad, la cual es necesario considerar con base en sus propiedades físicas; es decir el prestamista evalúa el inventario como posible garantí colateral de un préstamo, buscando productos con precios de mercado muy estables, que tengan mercados fáciles y que carezcan de propiedades físicas indispensables. En consideración a lo expresado por los autores se define el financiamiento de inventario como la solitud de préstamos a corto plazo el cual representa un activo circulante para obtener fondos basándose en la negociación de los bienes pignorados. De igual manera se dice que es una mejor opción después de las cuentas por cobrar.

En ese sentido (Cardozo 2016), manifiesta que según el activo biológico y la jurisdicción especifican, puede existir un mercado activo en el que haya precio de cotización fácilmente disponible. En tales casos, la medición de costo suele ser más gravosa y sujeta a la determinación del valor razonable, debido a las múltiples distribuciones de todos los costos de crianzas del animal, así como también la distribución de los costos indirectos correspondientes. No obstante, si existiera un mercado activo para terneros de dos semanas de edad, se podría determinar el valor razonable. Además, las gerencias suelen gestionar las actividades agrícolas a partir de los precios de mercado u otras medidas de valor corriente, y

\footnotetext{
"Visión de Futuro" Año 18, Volumen No 25 N² 2, Julio - Diciembre 2021 - Pág 40 - 62 URL de la Revista: http://visiondefuturo.fce.unam.edu.ar/index.php/visiondefuturo/index

URL del Documento: https://visiondefuturo.fce.unam.edu.ar/index.php/visiondefuturo/issue/view/21 
no a partir de los costos históricos. En estos casos, el modelo de valor razonable proporciona información más relevante sobre las actividades agrícolas que el modelo de costo.

Desde el punto de vista de los activos biológicos, los productos derivados de estos tales como la leche, frutas, carnes entre otros no serán reconocidos como activos biológicos, estos se reconocerán como inventario, es imperativo que los contadores de las empresas del sector agrícola, tenga en cuenta la valoración de sus inventarios tal como lo establece la sección 13 de las NIIF para Pyme, en cuanto a la valoración y medición de los inventarios.

\section{Metodología}

Esta investigación se enmarca en una metodología descriptiva. Según (Tamayo y Tamayo 2012. P25), comprende la descripción, registro, análisis e interpretación de la naturaleza actual, la composición de los procesos o fenómenos, trabaja sobre las realidades de hechos y su característica fundamental es presentar una interpretación correcta.

Por su parte (Finol y Camacho 2006). Expresa que el análisis documental, es el proceso de búsqueda, selección, lectura, registro, organización, descripción, análisis e interpretación de los datos extraídos de fuentes documentales existentes en torno a un problema, con el fin de dar respuesta a interrogantes en cualquier área del conocimiento humano.

De acuerdo al propósito, la investigación fue descriptiva, el cual se trabajó sobre realidades de hecho y su característica fundamental es la de presentar una interpretación correcta. Para (Hernández, Fernández y Baptista 2010), proponen la investigación descriptiva, como la que pretende "medir o recoger información de manera independiente o conjunta sobre los conceptos o las variables a los que se refieren" Por lo tanto, el tipo de investigación descriptiva, conduce al investigador hacia el conocimiento científico desde la descripción de un sujeto o problema sin influir sobre él. De tal manera que implica al mismo tiempo el uso de la observación con lo cual se fortalece el conocimiento. Por su parte, la investigación explicativa según (Hernández, Fernández y Baptista 2010), pretende establecer las causas de los eventos, sucesos o fenómenos que se estudian. Los estudios explicativos van más allá de la descripción de conceptos o fenómenos o del establecimiento de relaciones entre conceptos; es decir, están dirigidos a responder por las causas de los eventos y fenómenos físicos o sociales. Como su nombre lo indica, su interés se centra en explicar por qué ocurre un fenómeno y en qué condiciones se manifiesta, o por qué se relacionan dos o más variables (P. 83-84)

Analizando lo anterior se entiende que los estudios descriptivos buscan desarrollar una imagen o fiel representación del fenómeno estudiado a partir de sus características. Describir en este caso el tratamiento contable de los activos biológicos y los productos agrícolas. En el

\footnotetext{
"Visión de Futuro" Año 18, Volumen No 25 N² 2, Julio - Diciembre 2021 - Pág 40 - 62

URL de la Revista: http://visiondefuturo.fce.unam.edu.ar/index.php/visiondefuturo/index

URL del Documento: https://visiondefuturo.fce.unam.edu.ar/index.php/visiondefuturo/issue/view/21

ISSN 1668 - 8708 - Versión en Línea

E-mail: revistacientifica@fce.unam.edu.ar
} 
presente artículo se utilizó Método de búsqueda bibliográfica, exhaustiva, para acercamiento de la literatura existente, para lo cual se utilizó la búsqueda automatizada en base de datos, revisión de artículos y revistas, identificando los autores más destacados sobre el tema.

En cuanto al método de búsqueda exhaustiva, según (Benavent, González, González, y Arroyo. 2011). "constituye una etapa fundamental de todo proyecto de investigación y debe garantizar la obtención de la información más relevante en el campo de estudio, de un universo de documentos que puede ser muy extenso". La revisión bibliográfica o estado del arte corresponde a la descripción detallada de cierto tema o tecnología, pero no incluye la identificación de tendencias que puedan plantear diferentes escenarios sobre el desarrollo de la tecnología en cuestión y que permitan tomar decisiones estratégicas (Castellano, Torres, Rossero. 2005). Así mismo se realizó análisis de la información, conceptos y teorías sobre el tratamiento contable de los activos biológicos y los productos agrícolas.

\section{CONCLUSIONES}

Al Analizar el tratamiento contable de los activos biológicos y los productos agrícolas, se concluye que, en este tipo de actividad económica, la implementación de las NIIF es importante por cuanto sus estándares son más aproximados a la realidad, lo que facilita el proceso contable de los activos biológicos, mostrando unos financieros fiable y libre de errores significativos.

Por ello, es necesario llevar un control de todas las erogaciones que se dan con los activos biológicos en desarrollo, puestos que estos forman parte de él, además no se registran en las cuentas de resultados. Por otra parte, es imprescindible tener conocimiento del mercado, puesto que estos le permitirán conocer el valor razonable de las cosechas.

Por otra parte, al analizar las teorías y conceptos de los autores sobre La NIC 41, la cual recomienza a las empresas que:

A. Revele, por grupos o de otra manera, el monto del cambio en el valor razonable menos los costos estimados en el punto de venta, que se ha incluido en la ganancia o la pérdida neta del ejercicio y que se debe tanto a los cambios físicos como a los cambios en los precios.

B. Que la transformación biológica produce una variedad de cambios de tipo Físico, crecimiento, degradación, producción y procreación, en el que cada uno de estos aspectos es observable y valorizable. Cada uno de esos cambios físicos tiene una relación directa con los beneficios económicos futuros.

C. Que el cambio en el valor razonable de un activo biológico debido a la cosecha o recolección, es también un cambio de tipo físico.

\footnotetext{
"Visión de Futuro" Año 18, Volumen N²5 N², Julio - Diciembre 2021 - Pág 40 - 62

URL de la Revista: http://visiondefuturo.fce.unam.edu.ar/index.php/visiondefuturo/index

URL del Documento: https://visiondefuturo.fce.unam.edu.ar/index.php/visiondefuturo/issue/view/21

ISSN 1668 - 8708 - Versión en Línea

E-mail: revistacientifica@fce.unam.edu.ar
} 
D. Que la actividad agrícola está, a menudo, expuesta a riesgos naturales como los que tienen relación con el clima o las enfermedades. Si se produjese un evento de este tipo, que diese lugar a una partida de gastos o ingresos con importancia relativa, se revelará la naturaleza y cuantía de la misma, de acuerdo con lo establecido en la NIC 1

Por lo tanto, El Consejo Técnico de la Contaduría Pública (CTCP) expresa que los productos agrícolas cosechados o recolectados que procedan de activos biológicos deben ser sometidos, en el punto de cosecha o recolección, por su valor razonable menos los costos de venta. Por consiguiente, las normas a las que pertenece este grupo según la NIC 41 Grupo 1. NIC 41, "13 Los productos agrícolas cosechados o recolectados que procedan de activos biológicos de una entidad se medirán a su valor razonable menos los costos de venta en el punto de cosecha o recolección. Tal medición es el costo a esa fecha, cuando se aplique la NIC 2. Inventarios, u otras normas que sean de aplicación". "por su parte, en el grupo 2 NIIF para Pymes, 34.5. Los productos agrícolas cosechaos o recolectados que proceden de activos biológicos de una entidad se medirán a su valor razonable menos los costos de venta en el punto de cosecha o recolección. Esta medición será el costo a esa fecha, cuando se aplique las Sección 13 Inventarios u otras secciones de la NIIF que sea de aplicación, por lo tanto, la medición realiza en el punto de cosecha se considerará como costo de inventario en el evento que exista un proceso de conservación o transformación posterior.

Finalmente, las empresas que manejan los productos agrícolas cosechados 0 recolectados que procedan de activos biológicos deben ser sometidas, en el punto de cosecha o recolección, por su valor razonable menos los costos de venta. La norma indica que los activos biológicos se dividen en consumibles y para producir, los consumibles lo conforman los productos agrícolas o vendidos como activos biológicos, como las cabezas de ganado de la que se obtiene carne o las que se tiene para la venta, mientras que los vivos bilógicos para producir están conformados por todos aquellos que sean para la producción como el ganado para la producción de la leche, entre otros, así mismo nos muestra que dependiendo la utilidad del mismo si es para consumir o para producir, tienen diferentes formas de ser trataos en contabilidad, por lo tanto en la sección 4 "Estado de Situación Financiera" de la NIIF para Pymes exige la presentación por separado de los activos biológicos registrados al costo menos la depreciación acumulada y el deterioro del valor (párrafo 4.2(h)) y de los activos biológicos registrados al valor razonable con cambios en resultados (párrafo 4.2(i)).

Por lo tanto, las empresas del sector agrícolas deben ser conscientes que la continuidad de sus operaciones se ve afectada no solo por el comportamiento de los precios de los productos que comercializan, además de cómo se administran la transformación del activo biológico (animales vivos y plantas, entre otros), en este caso se alude a lo que expresan

\footnotetext{
"Visión de Futuro" Año 18, Volumen No 25 N², Julio - Diciembre 2021 - Pág 40 - 62

URL de la Revista: http://visiondefuturo.fce.unam.edu.ar/index.php/visiondefuturo/index

URL del Documento: https://visiondefuturo.fce.unam.edu.ar/index.php/visiondefuturo/issue/view/21

ISSN 1668 - 8708 - Versión en Línea

E-mail: revistacientifica@fce.unam.edu.ar
} 
(Romero 2011), (Warren y Col. 2007), (Besteiro y Marracín 2011), sobre la importancia de las, NIIF en las empresas, determinado que los usuarios de estas normas, requieren un nivel de información estándar para poder clasificar y evaluar su empresa.

\section{REFERENCIAS}

Accid R (2009): Valoración de empresas: Bases conceptuales y aplicaciones prácticas. Madrid, España. Profit Editorial. https://dialnet.unirioja.es/servlet/libro?codigo=363083 Arias, Fidias. (2006). El proyecto de investigación. Introducción a la metodología científica. Editorial Episteme. 5ª . Edición. Caracas. Venezuela. Librería virtual OZZY ALCID. https://www.academia.edu/42088727/EL_PROYECTO_DE_INVESTIGACI\%C3\%93N_ INTRODUC_METODOLOG\%C3\%8DA_CIENT\%C3\%8DFICA_6_FIDIAS_G_ARIAS

Bastián P (2008), Accounting Advisory Services NIC 41 Activos biológicos y prácticas Europeas de aplicación.Santiago de Chile. Chile. Audit. Tax. Advisore. https://docplayer.es/4907630-Activos-biologicos-accounting-advisory-services-nic-41activos-biologicos-y-practicas-europeas-de-aplicacion-diciembre-2008.html

Benavent, Aleixandre R, González Alcaide, G, González De Dios, J, y Alonso-Arroyo, A. (2011) Fuente de información bibliográfica (I). Fundamentos para la realización de búsquedas bibliográficas. Acta Pediátrica Española, 69 (3), pp. 131-136. http://www.scielo.org.co/scielo.php?script=sci_nlinks\&ref=000101\&pid=S0012-

$7353201400020002100001 \& \operatorname{lng}=e n$

Besteiro M y Marracín M (2011) Contabilidad Financiera Superior, ediciones Pirámide. https://www.edicionespiramide.es/libro.php?id=4100459

Block J y Hirt G (2015) Administración financiera. Editorial.: McGraw-Hill.

Cardozo Cuenca, Hernán. (2016), Contabilidad de entidades de economía solidaria bajo NIIF para PYME. Madrid. España. https://www.ecoeediciones.com/wpcontent/uploads/2015/07/Contabilidad-de-entidades-de-econom\%C3\%ADa-solidariabajo-NIIF-para-PyME-5ta-Edici\%C3\%B3n.pdf

Casteñanos, O. F. Torres, L.M. y Rossero, J. (2005). Aplicación de un modelo de inteligencia para la definición de estrategia tecnológica en diferentes niveles de complejidad institucional, en Seminario Latino-Iberoamericano de gestión tecnológica. Brazil. Memorias.

http://www.scielo.org.co/scielo.php?script=sci_nlinks\&ref=000105\&pid=S0012$7353201400020002100003 \& \operatorname{lng}=e n$

Chirino R. Marrufo R (2017), Tratamiento contables de la actividad agrícola bajo las normas internacionales de información Financiera. Publicaciones Legis, Bogotá Colombia.

\footnotetext{
"Visión de Futuro" Año 18, Volumen No 25 No 2, Julio - Diciembre 2021 - Pág 40 - 62

URL de la Revista: http://visiondefuturo.fce.unam.edu.ar/index.php/visiondefuturo/index

URL del Documento: https://visiondefuturo.fce.unam.edu.ar/index.php/visiondefuturo/issue/view/21

ISSN 1668 - 8708 - Versión en Línea

E-mail: revistacientifica@fce.unam.edu.ar
} 
https://xperta.legis.co/visor/temp_rcontador_73d4b753-e65d-492a-b734-

392c3604587b

Corona (2014), (Normas De Contabilidad En La Union Europea). Diccionario de Contabilidad, Auditoría y Control de Gestión (2008). https://www.librosuned.com/LU14220/Normasde-contabilidad-en-la-Uni\%C3\%B3n-Europea.aspx

Figuera C. (2018), Manual contable NIIF: Aplicación práctica.

Finol M. y Camacho H. (2006). El proceso de la investigación científica. 2da. Edición. Caracas Venezuela. Editorial

Ediluz.

https://scholar.google.com/citations?user=gPyxj10AAAAJ\&hl=es\#d=gs_md_citad\&u=\%2Fcitations\%3Fview_op\%3Dview_citation\%26hl\%3Des\%26user\%3DgPyxj10A AAAJ\%26citation_for_view\%3DgPyxj1oAAAAJ\%3AbEWYMUwl8FkC\%26tzom\%3D30 0

Gitman L. (2014). Principios de Administración Financiera. México: Edición Pearson Educación.

https://www.academia.edu/28949029/LIBRO_Principios_de_Administracion_Financiera _LAWRENCE_J_GITMAN

Hernández, Fernández y Baptista (2010). Metodología de la investigación. México Mc. Graw Hill.

https://www.esup.edu.pe/descargas/dep_investigacion/Metodologia\%20de\%20la\%20i nvestigaci\%C3\%B3n\%205ta\%20Edici\%C3\%B3n.pdf

International Accounting Standards Board (2011). https://www.iasplus.com/en/standards/ias Iriarte F (2010), Valoración de activos biológicos bajo la NIC 41, Utadeo, Bogota Colombia. https://expeditiorepositorio.utadeo.edu.co/bitstream/handle/20.500.12010/3730/Valorac i\%C3\%B3n\%20de\%20activos\%20biol\%C3\%B3gicos\%20bajo\%20la\%20NIC\%2041.\% 20Un\%20estudio\%20sobre\%20el\%20sector\%20pisc\%C3\%ADcola.pdf?sequence=1\&i sAllowed=y

La International Accounting Standards Board (2010).

Ley 1314 (2009) "por la cual se regulan los principios y normas de Contabilidad e Información Financiera y de aseguramiento de información aceptados en Colombia, se señalan las autoridades competentes, el procedimiento para su expedición y se determinan las entidades responsables de vigilar su cumplimiento. Diario Oficial. No. 47409 del 12 de julio. Bogotá D.C. http://www.ctcp.gov.co/publicaciones-ctcp/otros/ley-1314esquema/ley-1314-esquema

Ley 1819 de (2016), Reforma tributaria, Los artículos 92 al 95 sobre las disposiciones sobre la determinación de las rentas para la actividad pecuaria.

\footnotetext{
“Visión de Futuro" Año 18, Volumen N²5 N², Julio - Diciembre 2021 - Pág 40 - 62 URL de la Revista: http://visiondefuturo.fce.unam.edu.ar/index.php/visiondefuturo/index

URL del Documento: https://visiondefuturo.fce.unam.edu.ar/index.php/visiondefuturo/issue/view/21 
https://actualicese.com/activos-biologicos-en-la-reforma-tributaria-y-bajo-el-estandarinternacional-i/

Méndez C. (2006). Metodología: Diseño y desarrollo del proceso de investigación con énfasis en ciencias empresariales. Santafé de Bogotá: Limusa. https://www.casadellibro.com/libro-metodologia-diseno-y-desarrollo-del-proceso-deinvestigacion-con-enfasis-en-ciencias-empresariales-4-ed-incluyecd/9789589666982/1255269

Mora (2008), Diccionario de Contabilidad, Auditoría y Control de Gestión, Volume 3. Madrid. España. Editorial del Economista.

Norma Internacional de Contabilidad no $41 \quad$ (NIC 41). http://nicniif.org/files/NIC\%2041\%20Agricultura.pdf

Paraninfo C. (2007), contabilidad financiera. Un enfoque actual.

Romero J. (2011) Contabilidad Intermedia. Editorial: MCGRAW-HILL. (Tercera edición). https://www.academia.edu/34853458/Contabilidad_intermedia_3ed_romero

Sampedro, José Luis (2002) El mercado y la globalización. Barcelona, España. Destino, p. 65.

https://www.academia.edu/35351866/El_mercado_y_la_Globalizacion_Jose_Luis_Sa mpedro

Sección 34 (2015), de la norma internacional de Información financiera.

Tamayo y Tamayo Mario. (2012) El proceso de la investigación científica; Editorial Limusa Grupo Noriega Editores.

http://evirtual.uaslp.mx/ENF/220/Biblioteca/Tamayo\%20Tamayo-

El\%20proceso\%20de\%20la\%20investigaci\%C3\%B3n\%20cient\%C3\%ADfica2002.pdf Uriarte M (2006), Contabilidad Para la tomas de decisiones Madrid. España. Editorial del Economista. https://core.ac.uk/download/pdf/77269747.pdf

Van Horne y Wachowicz (2012). Fundamentos de Administración financiera (undécima ed.). México: Mc Graw Hill. https://www.academia.edu/17838510/Administraci\%C3\%B3n_Financiera_10ma_Ed_J ames_C_Van_Horne

Warren C, Reeves J y Duchac. (2015), Contabilidad Financiera 14aㅡ ed México: Mc Graw Hill. https://issuu.com/cengagelatam/docs/warren_issuu 


\section{RESUMEN BIBLIOGRÁFICO}

\section{Rubén Darío Marrufo García}

Licenciado en Contaduría Universidad Dr. José Gregorio Hernández, Magister en Gerencia empresarial, Dr. En Ciencias Gerenciales, Postdoctor en Gerencia de las Organizaciones (Urbe). Docente en la Universidad Dr. Rafael Belloso Chacin). Docente invitado por la Universidad Popular del Cesar, conferenciante nacional e internacional.

\section{Abel María Cano Morales}

Profesor Asociado Doctor. Exjefe Programa de Contaduría Pública, Exdirector de la Maestría en Tributación y Política Fiscal de la Universidad de Medellín. Actualmente Coordinador de Internacionalización del programa de Contaduría Pública y Docente Investigador de la facultad de Ciencias Económicas y Administrativas de la Universidad de Medellín. Líder del Grupo de Investigación Contables y Gestión Pública GIIP. Contador Público 1995. Especialista en Gerencia de Impuestos. 1996. ISDET-Universidad Externado de Colombia. Especialista en Derivados, futuros y opciones. 2005. Anglia Ruskin college price future group- Londres. Magister en Administración, 2000. Universidad Autónoma de Bucaramanga. Magister en Finanzas, 2003. Instituto Tecnológico de Estudios Superiores de Monterrey- México. Cum Laude. Doctor en Administración Publica, 2014, American Andragogi University, - Estados Unidos de Norteamérica. Sobresaliente. Certificación en Norma's. Londres 2007. The Institute of Internal Auditors de Londres. Certifications por ICAWEB- Londres, 2019. Programa de Capacitacion y Evaluacion en NIIF para Pymes. Diplomado en Didáctica Universitaria 2004. Universidad de Medellín. Diplomado en Montaje de Cursos en Plataforma AVA 2005. Servicio Nacional de Aprendizaje Sena. Diplomado en Tecnologías de Información y Comunicación 2005. Universidad de Medellín. Seminario de Divulgación Científica 2006. Universidad de Medellín. Diplomado en Conformación y Gestión de Grupos de Investigación. 2003. Universidad de Medellín. Par del CNA desde el año 2004, para Acreditación de programas Consejo Nacional de Acreditación. Par del MEN desde el año 2004, para Registro Calificado de Programas de Pregrado y Postgrado Ministerio de Educación Nacional. Par Internacional adscrito al SINAES de Costa Rica desde el año 2010, para Acreditación Internacional de Programas de Pregrado y Postgrado Ministerio de Educación de Costa Rica. Autor de 9 libros, 12 capítulos de libro y 70 artículos.

\footnotetext{
"Visión de Futuro" Año 18, Volumen No 25 N², Julio - Diciembre 2021 - Pág 40 - 62

URL de la Revista: http://visiondefuturo.fce.unam.edu.ar/index.php/visiondefuturo/index

URL del Documento: https://visiondefuturo.fce.unam.edu.ar/index.php/visiondefuturo/issue/view/21

ISSN 1668 - 8708 - Versión en Línea

E-mail: revistacientifica@fce.unam.edu.ar
} 